UCRL-102141

PREPRINT

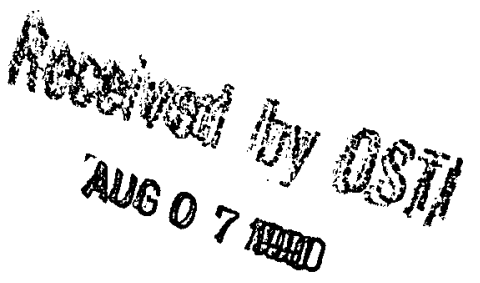

A Comparison of the Monte Carlo and the

Flux Gradient Method for Atmospheric Diffusion

Rolf Lange

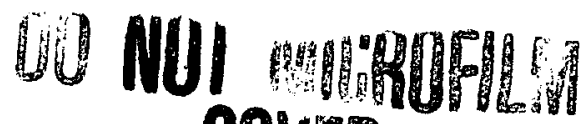

COUER

This paper was prepared for submittal to

The 18th NATO/CCMS International Technical Meeting on Air Pollution Modelling and Its Application,

Vancouver, Canada, May 13-17, 1990.

May 1990

This is a preprint of a paper intended for publication in a journal or proceedings. Since changes may be made before publication, this preprint is made available with the understanding that it will not be cited or reproduced without the permission of the author. 


\section{DISCLAIMER}

This document was prepared as an account of work sponsored by an agency of the U United Siates Government. Neither the United States Government nor the University Cof Caflifornia nor any of their employees, makes any warranty, express or implied, or assumes any legal liability or responsibility for the accuracy, completeness, or usefulness of any information. apparatus, product. or process disclosed, or represents that its use would not infringe privately owned rights. Reference herein to any specific commercial products, process, or service by trade name, trademark, manufacturer, or otherwise, does not necessarily constitute or imply its endorsement, recommendation, or favoring by the United States Government or the University of California. The views and opinions of authors expressed herein do not necessarily state or reflect those of the United States Government or the University of California, and shall not be used for advertising or product endorsement purposes. 


\section{DISCLAIMER}

This report was prepared as an account of work sponsored by an agency of the United States Government. Neither the United States Government nor any agency Thereof, nor any of their employees, makes any warranty, express or implied, or assumes any legal liability or responsibility for the accuracy, completeness, or usefulness of any information, apparatus, product, or process disclosed, or represents that its use would not infringe privately owned rights. Reference herein to any specific commercial product, process, or service by trade name, trademark, manufacturer, or otherwise does not necessarily constitute or imply its endorsement, recommendation, or favoring by the United States Government or any agency thereof. The views and opinions of authors expressed herein do not necessarily state or reflect those of the United States Government or any agency thereof. 


\section{DISCLAIMER}

Portions of this document may be illegible in electronic image products. Images are produced from the best available original document. 


\title{
A COMPARISON OF THE MONTE CARLO AND THE FLUX GRADIENT METHOD FOR ATMOSPHERIC DIFFUSION*
}

\author{
Rolf Lange
}

\author{
Atmospheric and Geophysical Sciences Division \\ Lawrence Livermore National Laboratory \\ Livermore, California 94550
}

UCRL--102141

DE9 0015040

\section{INTRODUCTION}

In order to model the dispersal of atmospheric pollutants in the planetary boundary layer, various methods of parameterizing turbulent diffusion have been employed. These approaches differ greatly in sophistication and complexity (Monin and Yaglom, 1971). Historically, the Gaussian plume models were the first dispersion models. The Gaussian formula is based on statistical theory and empirical observation of the horizontal and vertical standard deviation of the wind speed $\sigma_{y}$ and $\sigma_{z}$. In K-theory, the Eulerian diffusion-advection equation closure problem is circumvented by assuming a gradient transport paramaterization and the postulation of the turbulent diffusivity parameter $\mathrm{K}$, which must be provided empirically. The stochastic Markov chain (Monte Carlo) method employs generally the Langevin equation to model dispersion with the use of very many particles. The approach needs the empirical prescription of the wind velocity variances $\sigma_{u}$ and the Lagrangian integral time scales $T_{\mathrm{L}}$. All three methods have two things in common: they rely on some mathematical scheme and they need empirically derived diffusion parameters. (Higher order closure models are not part of this discussion.)

The purpose of this paper is to use a three-dimensional particle-in-cell transport and diffusion model to compare the Markov chain (Monte Carlo) method of statistical particle diffusion with the deterministic flux gradient (K-theory) method. The two methods are heavily used in the study of atmospheric diffusion under complex conditions, with the Monte Carlo method gaining in popularity partly because of its more direct application of turbulence parameters. The basis of comparison is a data set from night-time drainage flow tracer experiments performed by the U.S. Department of Energy Atmospheric Studies in Complex Terrain (ASCOT) program at the Geysers geothermal region in northern California. The domain of this complex terrain study is about $7 \times 10$ kilometers. The Atmospheric Diffusion Particle-in-Cell (ADPIC) model used is the main model in the Lawrence Livermore National Laboratory emergency response program: Atmospheric Release Advisory Capability (ARAC). As a particle model, it can simulate diffusion in both the flux gradient and Monte Carlo modes.

* Work performed under the auspices of the U.S. Department of Energy by the Lawrence Lawrence Livermore National Laoratory under contract No. W-7405-Eng-48. 


\section{MODEL DESCRIPTION}

ADPIC (Lange, 1978 and 1989) is a three-dimensional numerical particle-in-cell diffusion and transport model capable of simulating the time and space varying dispersal of atmospheric pollutants under complex conditions. It is a particle-in-cell model in which Lagrangian "mass" particles are transported inside a fixed Eulerian grid. The model solves the three-dimensional flux conservation equation,

$$
\frac{\partial \chi}{\partial t}+\nabla \cdot\left(\chi \vec{U}_{p}\right)=0
$$

$\chi$ is the pollutant concentration obtained by summing the particles in a given cell. $\vec{U}_{p}$ is a pseudo transport velocity defined as the sum of the mean advection velocity $\vec{U}_{a}$ and a diffusive velocity $\vec{U}_{d}$, all interpolated to individual particle positions.

$$
\vec{U}_{p}=\vec{U}_{a}+\vec{U}_{d}
$$

$\vec{U}_{a}$ is provided by a gridded mean wind field model MATHEW (Sherman 1978) which uses interpolated meteorological data and terrain information to produce a mass conservative wind field. The diffusion velocity $\vec{U}_{d}$ is computed in ADPIC depending on the type of diffusion theory chosen: either Monte Carlo or K-theory.

For $\mathrm{K}$-theory $\vec{U}_{d}$, the diffusion velocity, is obtained by the mathematical model of gradient transport,

$$
\vec{U}_{d}=-K \cdot \nabla \chi / \chi
$$

where $K$ is the diffusion coefficient, empirically derived for the vertical as

$$
K_{z}=\frac{k u_{*} z}{\phi(z / L)} e^{-\left(\frac{v_{g} z}{U_{*}}\right)}
$$

where $k$ is the Von Karman constant, $u_{*}$ is the friction velocity, $z$ is the height, above terrain $\phi(z / L)$ is an atmospheric stability function based on $z$ and the Monin-Obukhov scale length $L, V_{g}$ is the geostrophic wind and $h$ the height of the mixing layer (Businger and Arya 1974).

The horizontal diffusivity, $K_{h}$, is based on the semi-empirical expression (Draxler 1976)

$$
\sigma_{y}=\sigma_{\theta} U t\left(1+\frac{t}{\tau}\right)^{-1 / 2}
$$

combined with the analytical relationship

$$
K_{h}=\sigma_{y} d \sigma_{y} / d t
$$

where $\sigma_{y}$ is the horizontal standard deviation of the plume, $\sigma_{\theta}$ the standard deviation of the fluctuation of the wind direction, $U$ the local mean wind speed, $t$ is time, and $\tau$ is an empirical time constant. Because of the term $\nabla \chi / \chi$ in Eq. 3, the gradient theory approach to diffusion needs a grid-cell mesh. 
For Monte Carlo statistical diffusion, the diffusion velocity $\vec{U}_{d}$ is computed using the Langevin equation (Legg and Raupach 1982). The vertical component equation being,

$$
w(t+\Delta t)=a w(t)+b \sigma_{w} \zeta+(1-a) T_{L} \partial\left(\sigma_{w}^{2}\right) / \partial z
$$

where $w(t)$ is the vertical velocity at time $t, \zeta$ a random number from a Gaussian distribution with zero mean and unit variance, $T_{L}$ the Lagrangian integral time scale, $a=$ $\exp \left(\Delta t / T_{L}\right)$, and $b=\left(1-a^{2}\right)^{1 / 2}$. The last term in Eq. 7 allows for inhomogeneous turbulence in which $\sigma_{w}$ and $T_{L}$ can vary with height, $z . \sigma_{w}$ and $T_{L}$ are empirical parameters which are computed from the following equations (Hanna 1981),

$$
\sigma_{w}=1.3 u_{*}(1-z / h) ; T_{L}=0.08 h / u_{*} \frac{(z / h)^{0.8}}{1-z / h} .
$$

The two horizontal components of $\vec{U}_{d}$ are computed using equations of the same form as Eq. 7 without the last term which deals with the vertical inhomogeneity of turbulence. Similarly, the prescriptions for the horizontial wind variances $\sigma_{u}$ and $\sigma_{v}$ and time scales $T_{L}$ follow the same functional forms as shown in Eq. 8. With the Monte Carlo method, the particles are totally independent from one another and no grid is needed to calculate the diffusion velocities.

\section{DESCRIPTION OF THE EXPERIMENT}

In 1978 the Department of Energy developed a program aimed at atmospheric studies in complex terrain (ASCOT). The ASCOT program was designed to develop the technology needed to assess atmospheric properties and the impact of energy sources on air quality in areas of complex terrain. The initial study site was the Geysers geothermal resource area located approxiamtely $120 \mathrm{~km}$ north of San Francisco, California, and the purpose was to study nocturnal air drainage flow.

The data set used here is one of five tracer release experiments in the Anderson Springs Valley in the Geysers in September 1980 (Gudiksen, 1983). The experiments consisted of obtaining meteorological and tracer release data over the area of the Anderson Springs Valley during nighttime drainage flow. The experiments began at 2300 PST and ended at approximately 0500 PST. Anderson Springs Valley is surrounded by Boggs Mountain to the northeast, by Cobb Mountain to the north and by Pine Mountain to the southwest, and forms a bowl shaped drainage regime for the Putah, Gunning, Anderson and Bear Creeks, opening towards the east. It has rugged topography and a ground cover varying from bare soil to forest canopy. Figure 1 shows the geography of the Anderson Springs Valley, the meteorological measurement, tracer release, and sampler locations.

The experiment chosen was on the night of September 19/20, during which 3 one-hour simultaneous and distinguishable surface tracer releases were conducted ( 2 perfluorocarbons, 1 sulfur hexafluoride) from the Anderson', Gunning and Putah creeks. Average concentrations were sampled at some 60 sampler locations and two vertical profile stations throughout the area. Averaging times varied from 10 minutes to 2 hours. In this study, the tracer data from only the Anderson Creek $(\mathrm{PMCH})$ was used providing some 170 samples. 


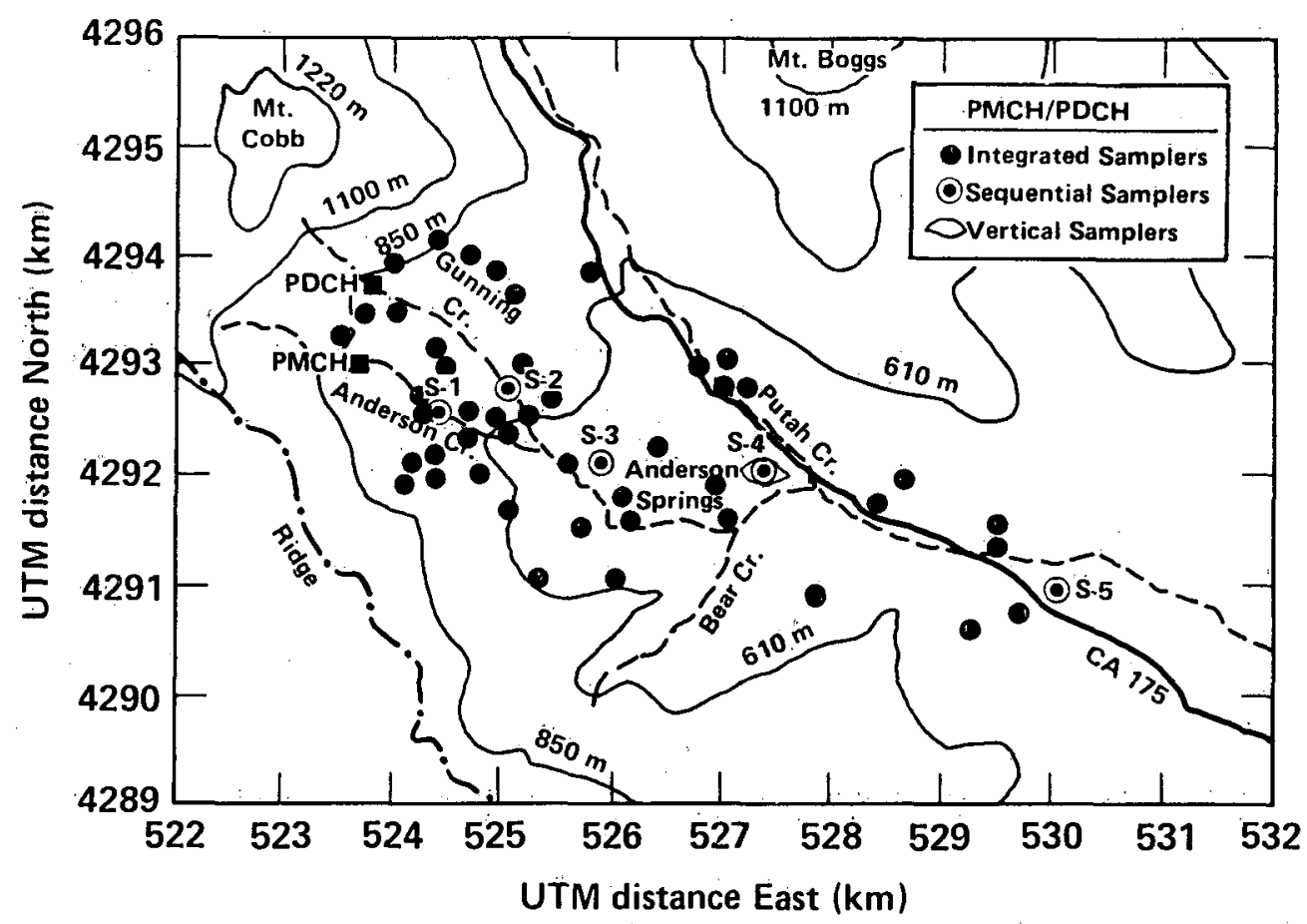

Fig. 1. Sampling and traces release locations for the 1980 Geysers Anderson Creek Valley experiments. The solid squares designate tracer release points.

The extensive meteorological data were collected by surface anemometers, tower anemometers, tethersondes accoustic sounders, and tetroons, providing $\mathrm{M} / \mathrm{A}$ with 47 surface stations and 8 vertical profiles of wind speed and direction as input (Fig. 1), plus the necessary information on stability and mixing height. All six hours during this night were stable with good air drainàge flow developing.

\section{RESULTS AND DISCUSSION}

Figure 2 shows a typical advection wind field at $40 \mathrm{~m}$ above terrain for the Anderson Valley at 0100 PST. The convergence of the drainage winds towards the center of the bowlshaped valley and the outflow to the southeast are quite evident. The heavy dashed lines are the four main drainage creeks and the dot-dashed line indicates the mountain ridge line. The wind vectors are drawn at every other grid point. Figure 3 shows an example of the ADPIC particle plume representing the tracer distribution at 0100 PST, two hours after the start of the one-hour release. The distribution shows little similarity with a wellbehaved plume. The pattern is short and disorganized with a shape intermediate between that of a plume and a puff. This heterogeneity in the plume structure is well-supported by the wide fluctuations shown by the measured tracer concentrations, which at times varied by a factor of 5 over a distance of $50 \mathrm{~m}$.

In the evaluation of the quantitative differences between $\mathrm{K}$-theory and the Monte Carlo method of diffusion in comparison to measured tracer concentrations, Figs. 4 and 5 show the sequential surface air tracer concentrations for 20 -minute averages at the three locations S-1, S-4, and S-5 as identified in Fig. 1. Figure 4 depicts the comparison between 


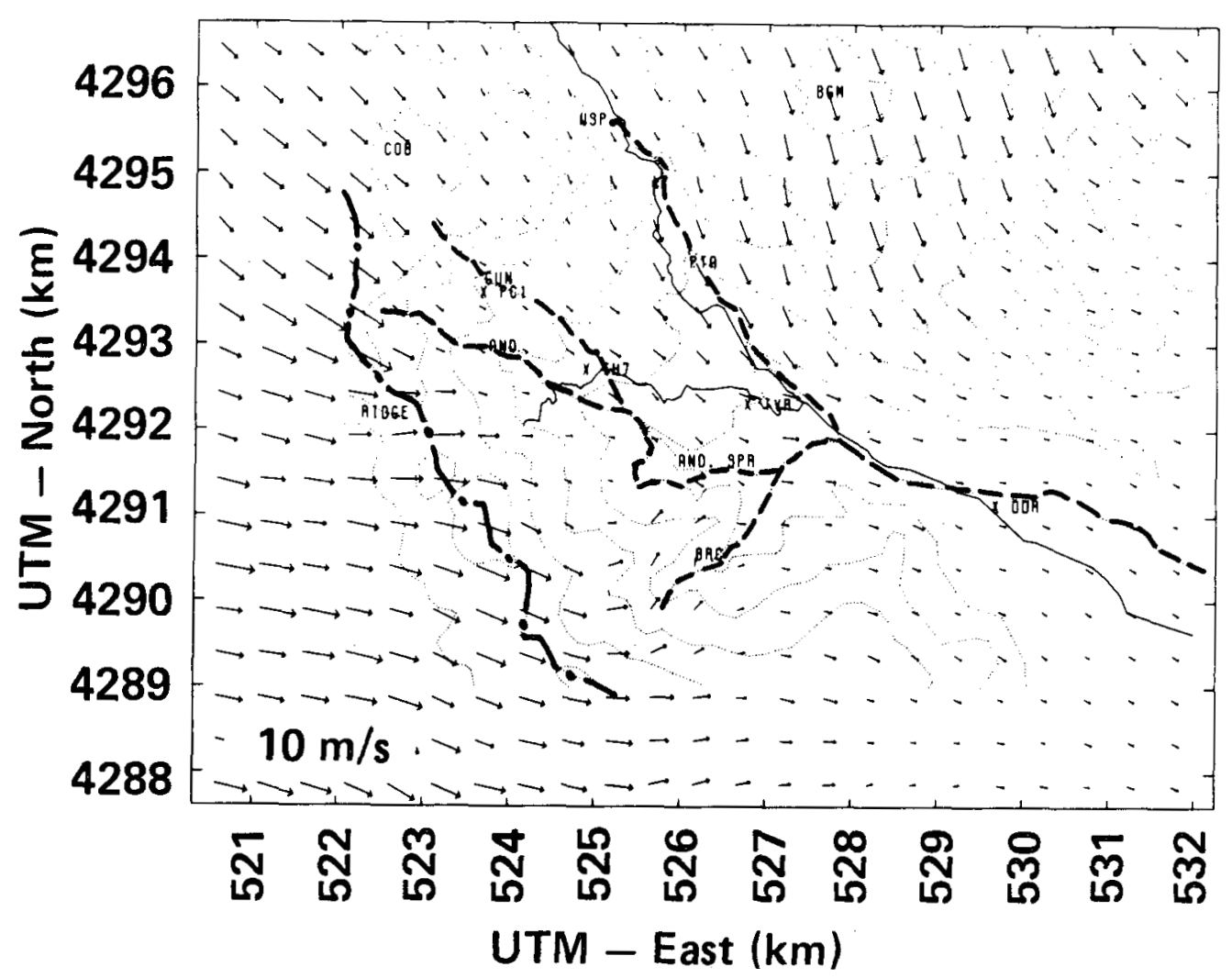

Fig. 2. MATHEW advection wind field $40 \mathrm{~m}$ above terrain for the Anderson Valley at 0100 PST.

the plume modeled by the K-theory method and measurements, and Fig. 5 the same for the Monte Carlo method. In each case, the arrival time of the modeled plume is late by 10 to 40 minutes as a result of lower wind speed coming from the advection wind field model. Also, in both cases, the modeled plume is "shorter," an effect that can be traced to the lack of ability of the model to take into account the drag effects of terrain and vegetation (trees) on the real tracer plume. Overall the differences between the two diffusion methods as shown in Figs. 4 and 5 are small.

It is difficult to devise a statistical method that in all cases adequately describes a model's performance in complex terrain. The standard correlation coefficient is used sometimes, although a few points can overly influence the entire results. Such points are typically located close to the tracer release point, where high concentrations are present, and the plumes are narrow so that spatial resolution is critical. Especially in complex terrain, a difference of $5^{\circ}$ in the angle of the computed plume trajectory can produce outlying points that completely overshadow the statistics and the performance of the model in the rest of the domain under study. Thus, another method, which is less biased by a few high concentrations, was selected for comparing the relative accuracy of the K-theory and Monte Carlo diffusion schemes.

This method involves a band analysis which equally weights the model performance over the entire spatial domain of interest by using the ratio of measured to computed 


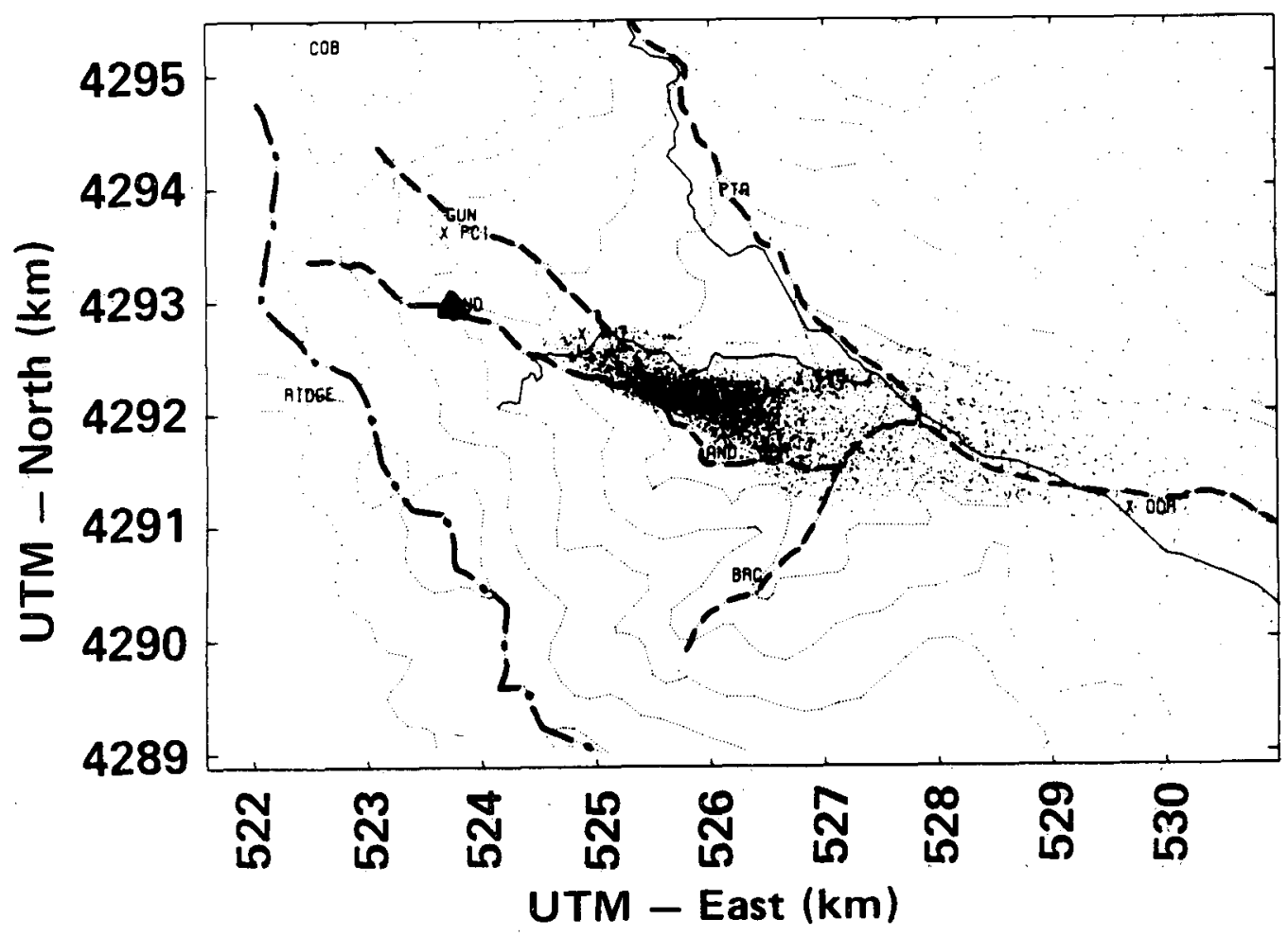

Fig. 3. ADPIC plume simulation example representing the tracer release in the Anderson Valley at 0100 PST one hour after the end of release. Solid triangle designates location of release.

tracer concentrations within the entire domain. A factor $R$ is computed for each pair of measurements $\left(C_{m}\right)$ and model calculations $\left(C_{c}\right)$ which represents the ratio between the two. The percentage of sample comparisons within a factor $R$ are plotted as a function of $R$. The definition of $R$ is

$$
R=C_{m} /\left(C_{c}+B\right), \text { except when } \mathrm{R}<1 \text {, then } \mathrm{R} \equiv 1 / \mathrm{R} .
$$

Here $B$ is background which is added to $C_{c}$. If both $C_{m}$ and $C_{c}$ are zero, the sample is disregarded. The average tracer background concentrations ranged from 0.01 to $0.03 \mathrm{ppt}$, which are small in comparison with most measurements. Background is included in the computed concentrations because the model does not provide background, and to avoid division by zero in the calculation of $R$ when $C_{c}$ is zero at some sampler location.

Figure 6 shows the percentage of measured samples agreeing with those computed to within a factor $R$ as defined above. The curves show that the Monte Carlo method gives consistently slightly better results. It does considerably better when looking at the residual defined as the difference between measured and computed concentrations shown in the figure. This is due to the Monte Carlo method providing a better simulation of the high measured concentrations near the source. 


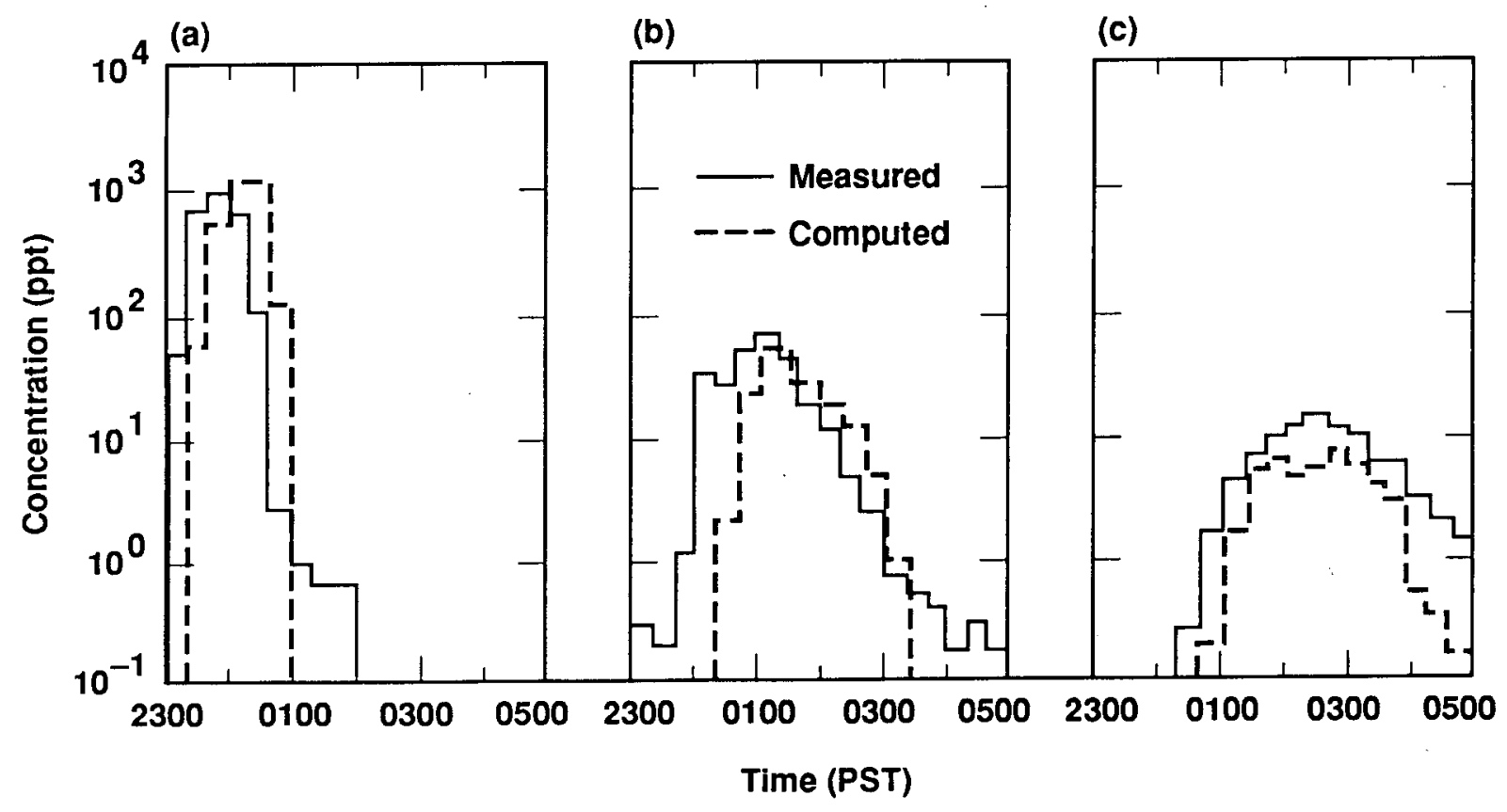

Fig. 4. K-theory computed vs. measured concentrations of the Anderson Creek tracer release in parts-per-trillion (ppt) at the sequential sampler locations: (a) S-1, (b) S-4, (c) S-5, plotted against time (see Fig. 1 for locations).

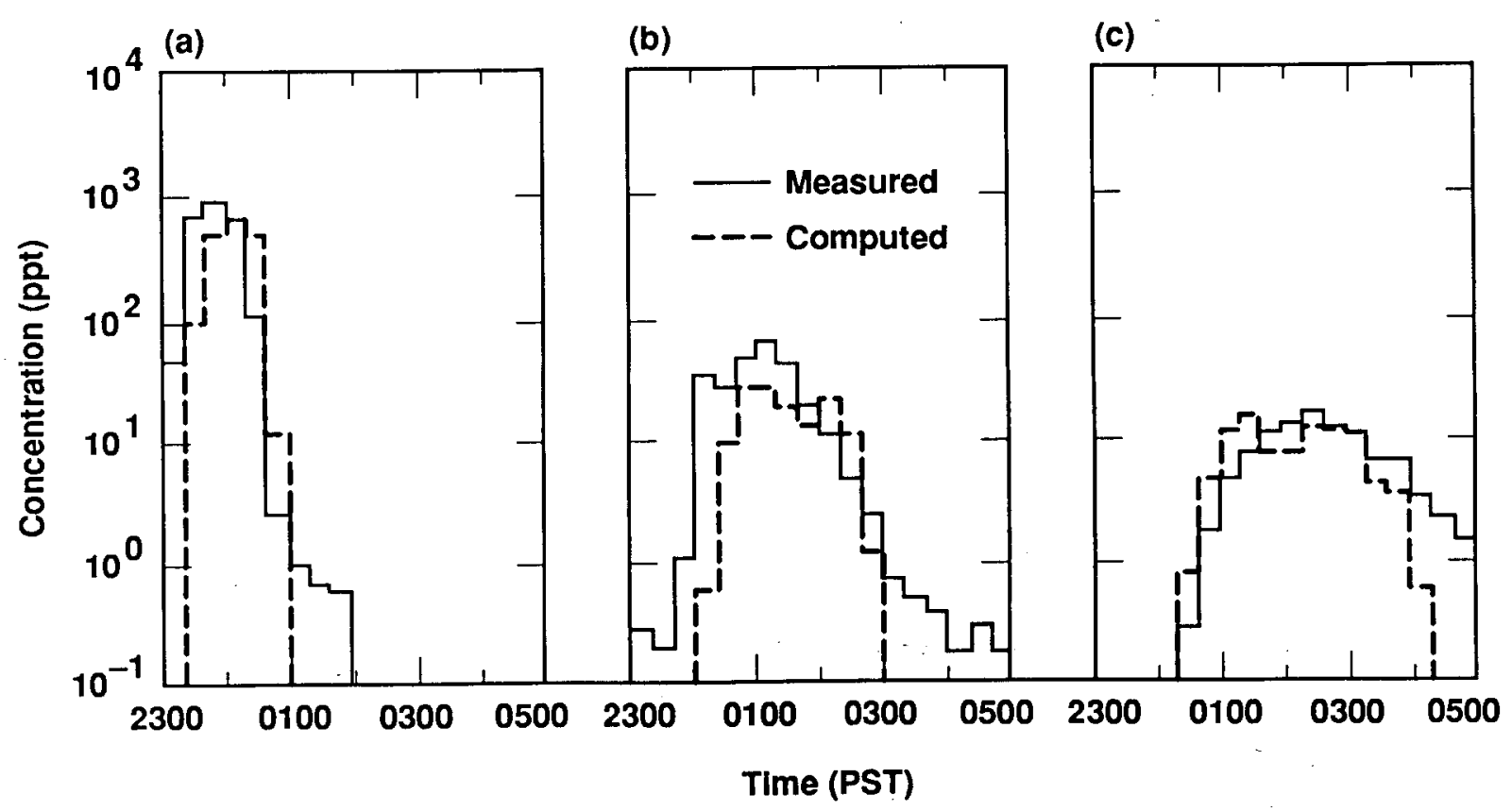

Fig. 5. Same as Fig. 4 except for Monte Carlo method. 
Name of problem: Geysers Night 4, PMCH \# of samples = $173 \mathrm{MC} / 170 \mathrm{G}$

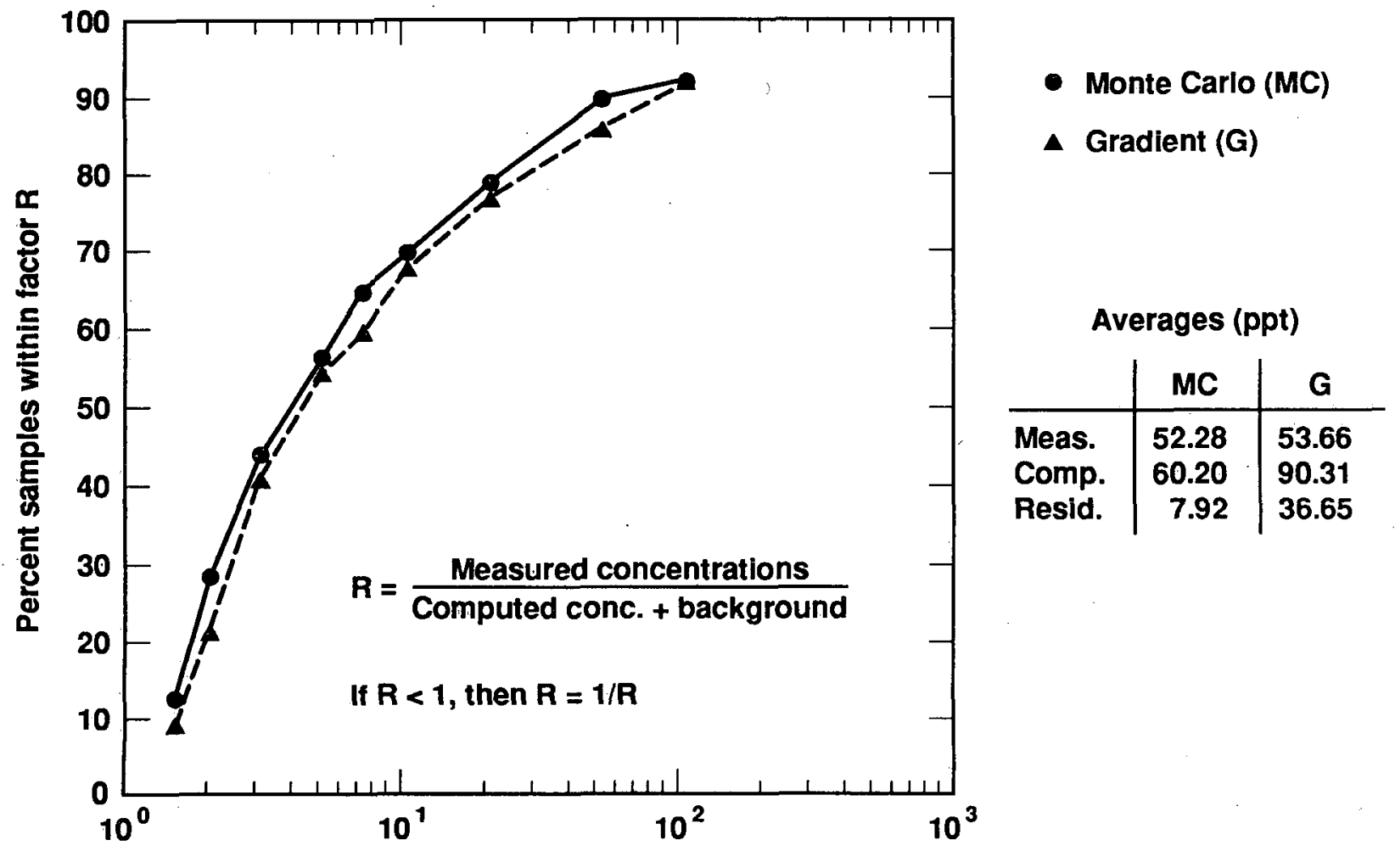

Factor $\mathbf{R}$

Fig. 6. Percentage of measured samples agreeing with those computed to within a factor $R$ (as defined in the figure) for the Anderson Creek tracer plume comparison between $\mathrm{K}$-theory and Monte Carlo diffusion. Also shown are the average measured and computed concentrations on the residuals in (ppt).

\section{CONCLUSIONS AND COMMENTS}

In comparing the simulations derived from the three-dimensional particle-in-cell diffusion model ADPIC, in both its gradient diffusion ( $\mathrm{K}$-theory) and Monte Carlo modes, against the results from a tracer release conducted in complex terrain during night time stable flow, the Monte Carlo method of diffusion gave slightly, but consistently better results when comparing measured and computed concentrations. This is encouraging because the Monte Carlo method of statistical diffusion provides advantages over the K-theory method. It represents both mathematically and physically a more fundamental approach to diffusion because (1) it is stochastic and, hence, does not depend on the concentration distribution, (2) it does not require a grid mesh to calculate gradients since the stochastic particles are independent of each other, and (3) it relies on diffusion parameters like $\sigma_{w}$ and $T_{L}$ which are more fundamentally linked to the turbulent diffusion regimes in the atmosphere than $\mathrm{K}$ profiles.

The following comments made for the case of vertical diffusion are equally valid for its horizontal components. Both the Monte Carlo and the $\mathrm{K}$-theory methods (as is also 
true for the Gaussian method mentioned in the introduction), require diffusion coefficient profiles of one kind of another, i.e., $\mathrm{K}$ or $\sigma_{w}$ and $T_{L}$. The profiles used in this study are shown in Eqs. 4 and 8. The strong, proportional dependence of the diffusion velocity $\vec{U}_{d}$ on $\mathrm{K}$ is evident from Eq. 3. The sensitivity of $\vec{U}_{d}$ to $\sigma_{w}$ and $T_{L}$ is not so immediately clear (Eq. 7). Initial numerical experiments with ADPIC, which are outside the scope of this paper, indicate a strong sensitivity of $\vec{U}_{d}$ to $\sigma_{w}$ and a rather weaker one to $T_{L}$. Presently, there is very little information on $\sigma_{w}$ and $T_{L}$ profiles available. Data on $\sigma_{w}$ are becoming more frequent through field experiments, but $T_{L}$ remains a rather elusive quantity. More research is needed to provide these profiles because numerical experiments indicate that the differences in $K, \sigma_{w}$ and $T_{L}$ parameterizations may well outweigh the difference between the $\mathrm{K}$-theory and Monte Carlo diffusion methods.

With regard to the relative computer time requirements, an ADPIC calculation with the Monte Carlo method showed a 10-percent savings over the $\mathrm{K}$-theory gradient method in this limited study. While the Monte Carlo method saves the need to calculate concentration gradients in a three-dimensional grid, it makes frequent calls to Gaussian distributed random number generators which is time consuming.

\section{ACKNOWLEDGEMENTS}

I would like to thank Leonard A. Lawson for programming the Monte Carlo diffusion into ADPIC, which was previously exclusively a $K$-theory code, and for doing most of the computations.

\section{REFERENCES}

Businger, J.A. and S.P.S. Arya, 1974, "Height of the Mixed Layer in the Stably Stratified Planetary Boundry Layer," Advances in Geophysics, Academic Press, 18A, 73-92.

Draxler, R.R., 1976, "Determination of Atmospheric Diffusion Parameters," Atmos. Environ., 10, 99-105.

Gudiksen, P.H., 1983, ASCOT Data from the 1980 Field Measurement Program in the Anderson Creek Valley, California, Lawrence Livermore National Laboratory Report \#UCID-18874-80.

Hanna, S.R., 1981, "Applications in Air Pollution Modeling," Atmospheric Turbulence and Air Pollution Modelling, F.T.M. Nieuwstadt and H. Van Dop, Editors, D. Reidel Publishing Co., Dortrecht/Boston/Lancaster, 1981.

Lange, R., 1978, "ADPIC-A Three-Dimensional Particle-in-Cell Model for the Dispersal of Atmospheric Pollutants and Its Comparison to Regional Tracer Studies, J. Appl. Meteoro. 17, 320-329, 1978.

Lange, R., 1989, "Transferability of a Three-Dimensional Air Quality Model Between Two Different Sites in Complex Terrain," J. of Appl. Meteoro., Vol. 28, No. 7, July 1989.

Legg, B.J., and M.R. Raupach (1982). "Markov Chain Simulation of Particle Dispersion in Inhomogeneous Flows: The Mean Drift Velocity Induced by a Gradient in Eulerian Velocity Variance," Boundary-Layer Met. 24, 3-13. 
Monin, A.S., and A.M. Yaglom, 1971, Statistical Fluid Mechanics: Mechanics of Turbulence, 1, MIT Press.

Sherman, C.A., 1978, "A Mass-Consistent Model for Wind Fields Over Complex Terrain,". J. Appl. Meteor. 17, 312-219. 


\section{DO NUI COUER
COHESHE}

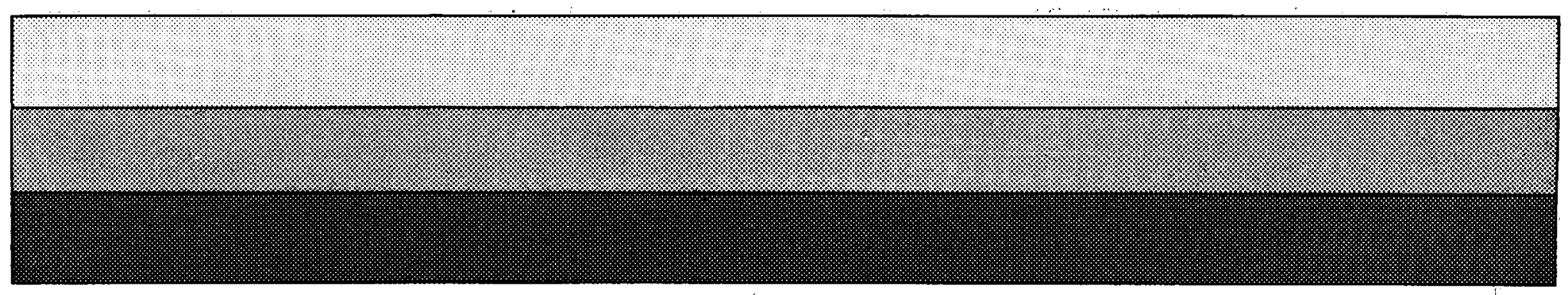

